\title{
Computer-Aided Design of Microstrip GaAs Mesfet Amplifiers
}

\author{
Nielsen, Niels Ole
}

Published in:

Microwave Conference, 1976. 6th European

Link to article, DOI:

10.1109/EUMA.1976.332343

Publication date:

1976

Document Version

Publisher's PDF, also known as Version of record

Link back to DTU Orbit

\section{Citation (APA):}

Nielsen, N. O. (1976). Computer-Aided Design of Microstrip GaAs Mesfet Amplifiers. In Microwave Conference, 1976. 6th European (pp. 596-600). IEEE. https://doi.org/10.1109/EUMA.1976.332343

\section{General rights}

Copyright and moral rights for the publications made accessible in the public portal are retained by the authors and/or other copyright owners and it is a condition of accessing publications that users recognise and abide by the legal requirements associated with these rights.

- Users may download and print one copy of any publication from the public portal for the purpose of private study or research.

- You may not further distribute the material or use it for any profit-making activity or commercial gain

- You may freely distribute the URL identifying the publication in the public portal

If you believe that this document breaches copyright please contact us providing details, and we will remove access to the work immediately and investigate your claim. 


\section{Nielsen}

\section{ABSTRACT}

Results on computer-aided design of broadband GaAs MESFET amplifiers in microstrip is presented. The analysis of an amplifier is based on measured scattering parameters and a model of the microstrip structure, which includes parasitics and junction effects. The optimized performance of one stage amplifiers with lossless distributed matching elements is presented. Realized amplifiers are in good agreement with the theory. One stage amplifiers with a $1 \mu \mathrm{m} F E T$ in chip form exhibit $5.8 \mathrm{~dB}$ of gain in the range 8-12 GHz, while a gain of $4.5 \mathrm{~dB}$ from $4-8 \mathrm{GHz}$ has been obtained with a packaged $I \mu \mathrm{m}$ FET.

\section{INTRODUCTION}

This paper presents results on computer-aided design of broadband one stage amplifiers in microstrip with $1 \mu \mathrm{m}$-gate GaAs MESFET's and the measured performance of realized amplifiers. The scattering parameters of both packaged and chip transistors have been measured precisely by the use of micror strip standards. The amplifier network consists of lossless distributed matching elements as shunt stubs and coupled microstrip lines. The amplifier analysis incorporates microstrip junction effects and parasitics and the amplifiers are designed for a low VSWR at one port and a flat overall gain by selectively mismatching the other port with the aid of a minimax optimization routine.

\section{DEVICE MOUNTING AND CHARACTERIZATION}

The GaAs MESFET's are of the GAT 3 type from Plessey having a gatelength of $1 \mu \mathrm{m}$. In chip form the FET has been mounted on a disc (COD) in a drilled hole in a $.635 \mathrm{~mm}$ thick alumina substrate. The GAT 3 is also available in a IID ( $P$ 102) package and packaged devices have been used in conjunction with a $.38 \mathrm{~mm}$ thick duroid substrate $\left(\varepsilon_{r}=2.4\right)$.

Precise scattering parameter measurements have been performed by the use of a manual network analyzer and by off-line correction for connector and test equipment errors. This has been done by using microstrip reflection standards as a short, an open corrected for the end effect and a match realized by a $50 \Omega$ chip resistor. Measured $S$ parameters of a GAT 3 chip mounted on a COD in alumina substrate are shown in fig. 1 for a gate bias $\mathrm{V}_{1}=\mathrm{OV}$. The reference planes are at the beginning of the bond wire leadifg to the FET. The chip was potentially unstable up to $10.5 \mathrm{GHz}$ having a calculated maximum available gain MAG of $8 \mathrm{~dB}$ at $12 \mathrm{GHz}$ and a slope of nearly $5 \mathrm{~dB} \mathrm{pr}$. Octave for the unilateral gain. A packaged device exhibited a calculated MAG of $9.6 \mathrm{~dB}$ at $4 \mathrm{GHz}$ and $\mathrm{MAG}=5.3 \mathrm{~dB}$ at $8 \mathrm{GHz}$.

* Electromagnetics Institute, Technical University of Denmark. DK-2800 Lyngby, Denmark. 
Fig. 1 Measured S parameters of a GAT 3 chip

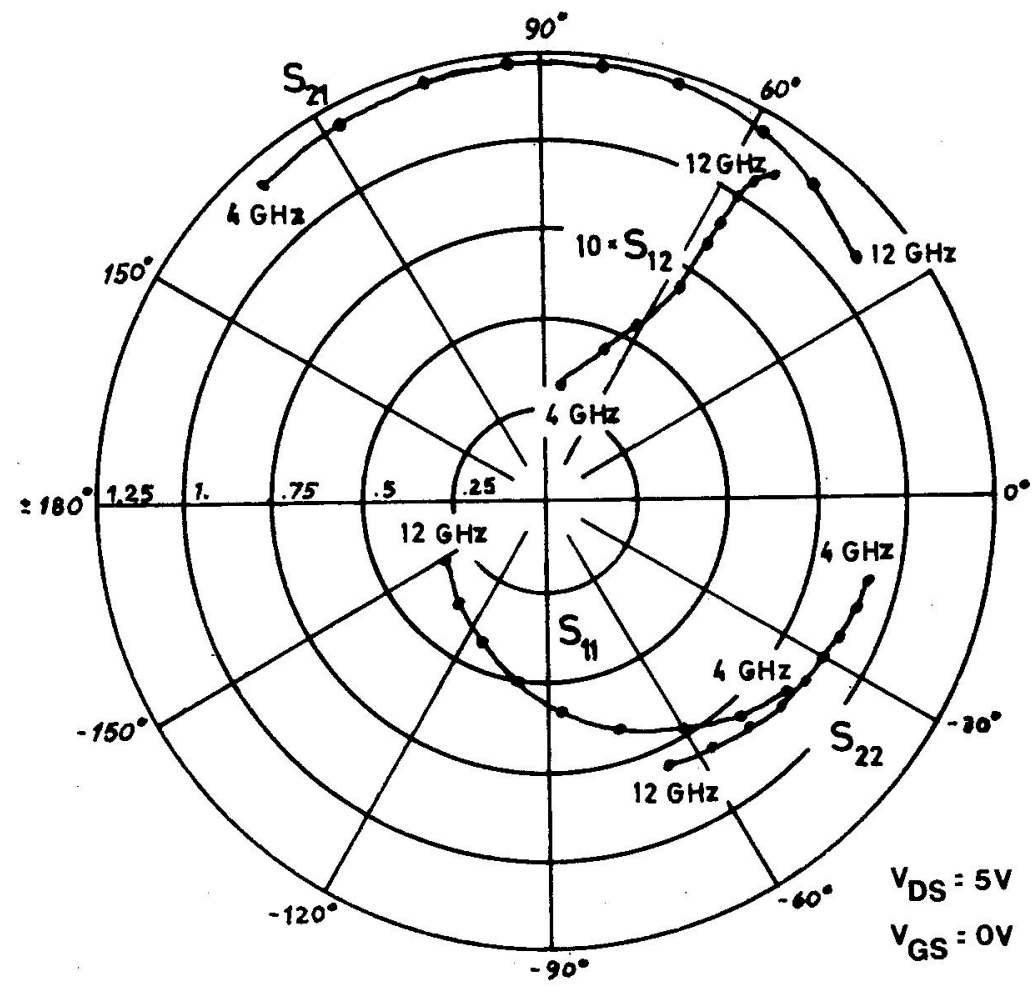

\section{AMPLIFIER DESIGN}

It is preferable to design the input and output matching network of an one stage amplifier individually. By using a non-linear minimax optimization routine [1] one of the matching networks is designed for a low VSWR while the other is designed to exhibit a slope of the transmission that compensate the intrinsic gain taper of the FET. With both matching networks connected to the FET the overall gain has to be optimized for a flat response due to finite isolation of the FET. Distributed lossless microstrip elements as a transmission line, an open and short circuited stub and two coupled lines, where two opposite ports are open circuited, have been used. The description of these elements and the junction between them is based on equations presented in [2] - [4]. At the end of an amplifier design a more precise but also time consuming procedure can be used for analysis of the coupled lines.

Liechti and Tillman [5] have presented an excellent design method, where the matching for a low VSWR was obtained by $\lambda / 4$ resonators coupled alternately by impedance and admittance inverters. A similar structure with $\lambda / 2$ resonators coupled only by impedance inverters can also provide a good broadband match. The impedance inverters are realized by shorted shunt lines with a high characteristic impedance. In general an even better result can be obtained by using a structure of shunting parallel resonators and series resonators, realized by $\lambda / 4$ short circuited shunt stubs coupled by $\lambda / 4$ transmission lines. This structure leeds to physically large T-junction, which can be reduced by realizing a parallel resonator as two shorted shunt stubs in parallel or an $\lambda / 2$ open circuited stub.

The structure with $\lambda / 4$ resonators is also suitable for providing a prescribed transmission slope, such that the network is matched at the upper band 
edge frequency and selectively mismatched at the lower edge. Shorted stubs enables the dc bias of the FET, while dc blocking can be obtained by replacing a series resonator by two coupled lines of a quarter wavelength, where two opposite ports are open circuited.

\section{EXAMPLES OF BROADBAND AMPLIFIERS}

In fig. 2 is shown the performance of a 8-12 $\mathrm{GHz}$ amplifier in alumina with a GAT-3 chip. The input is matched by one $\lambda / 2$ resonator and two impedance inverters, while the output compensates the gain taper by a high impedance line to resonate the output of the FET, a shunt resonator and one transformer (fig. $2 \mathrm{~b}$ ). A gain of $5.8 \mathrm{~dB} \pm .1 \mathrm{~dB}$ has been obtained. Fig. 3 shows the best result obtained with the shunting parallel resonator structure. As the input of the FET (fig. l) is nearly resonated at $12 \mathrm{GHz}$ the first T-junction degrades the performance of this structure. The measured performance of a realized amplifier is also shown ( $f i g .3 a$ ) and a fine agreement has been obtained. The deviation is mainly due to a shorter drain bonding wire in the realized amplifier.

For a 4-8 GHz amplifier with a packaged GAT 3 the best result was obtained by the structure with parallel shunt resonators. A gain of $4.5 \mathrm{~dB} \pm .2 \mathrm{~dB}$ and an output VSWR less than 2.6 has been realized. The calculated and measured performance is shown in fig. 4 together with the structure of the amplifier circuit. An excellent agreement between theory and the measurements has been obtained. If the transmission line in the output network of the amplifier in fig. $4 \mathrm{~b}$ is replaced by two coupled lines (fig. 5b) to prom vide a dc block a similar theoretical performance can be obtained (fig. $5 \mathrm{a}$ ).

\section{CONCLUSION}

One stage MESFET amplifiers in microstrip have been designed by a computeraided technique, where junction effects and parasitics in the network structure is taken into account. The measured performance of realized untuned amplifiers is in good agreement with the theory. This shows the feasibility of making reproducible designs of broadband multi stage amplifiers.

\section{ACKNOWLEDGEMENT}

The GaAs MESFET's were supplied by the Plessey Company, Allen Clark Research Centre, Towcester, England. The author is indebted to Dr. N. Slaymaker of the Allen Clark Research Centre and to Dr. G. Biethan, formerly at the Technical University, Aachen, Germany for valuable discussions. This work has been supported by the Danish Government Fund for Scientific and Industrial Research.

\section{REFERENCES}

[1] K. Madsen, O. Nielsen, H. Schjær-Jacobsen, and L. Thrane, "Efficient Minimax Design of Networks without Using Derivatives", IEEE Trans. MTT-23, pp. 803-809, Oct. 1975.

[2] E.O. Hammerstad, "Equations for Microstrip Circuit Design", Proc. 5'th European Microwave Conf., Hamburg 1975, pp. 268-272.

[3] A. Farrar and A.T. Adams, "Matrix Methods for Microstrip Three-Dimensional Problems", IEEE Trans. MTT-20, pp. 497-504, Aug. 1972.

[4] S. Akhtarzad, T.R. Rowbotham, and P.B. Johns, "The Design of Coupled Microstrip Lines", IEEE Trans. MTT-23, pp. 486-492, June 1975. 


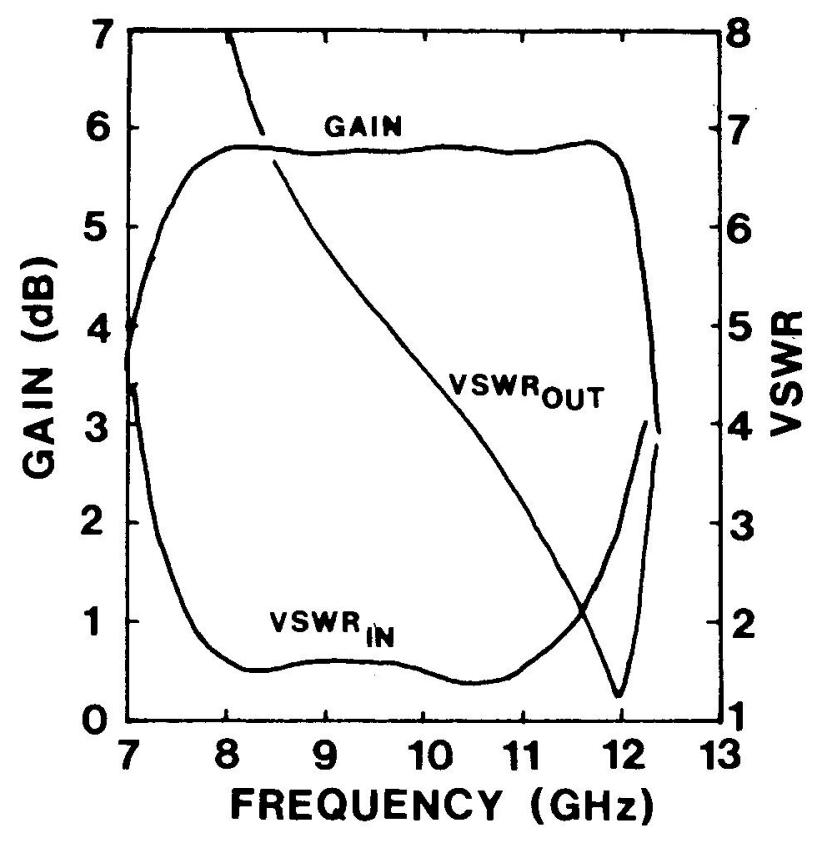

FIG 2a

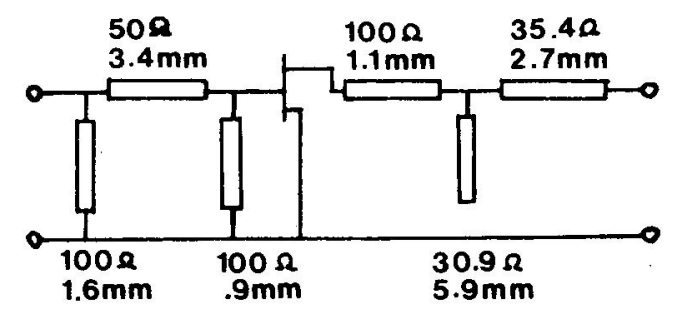

FIG 2 b

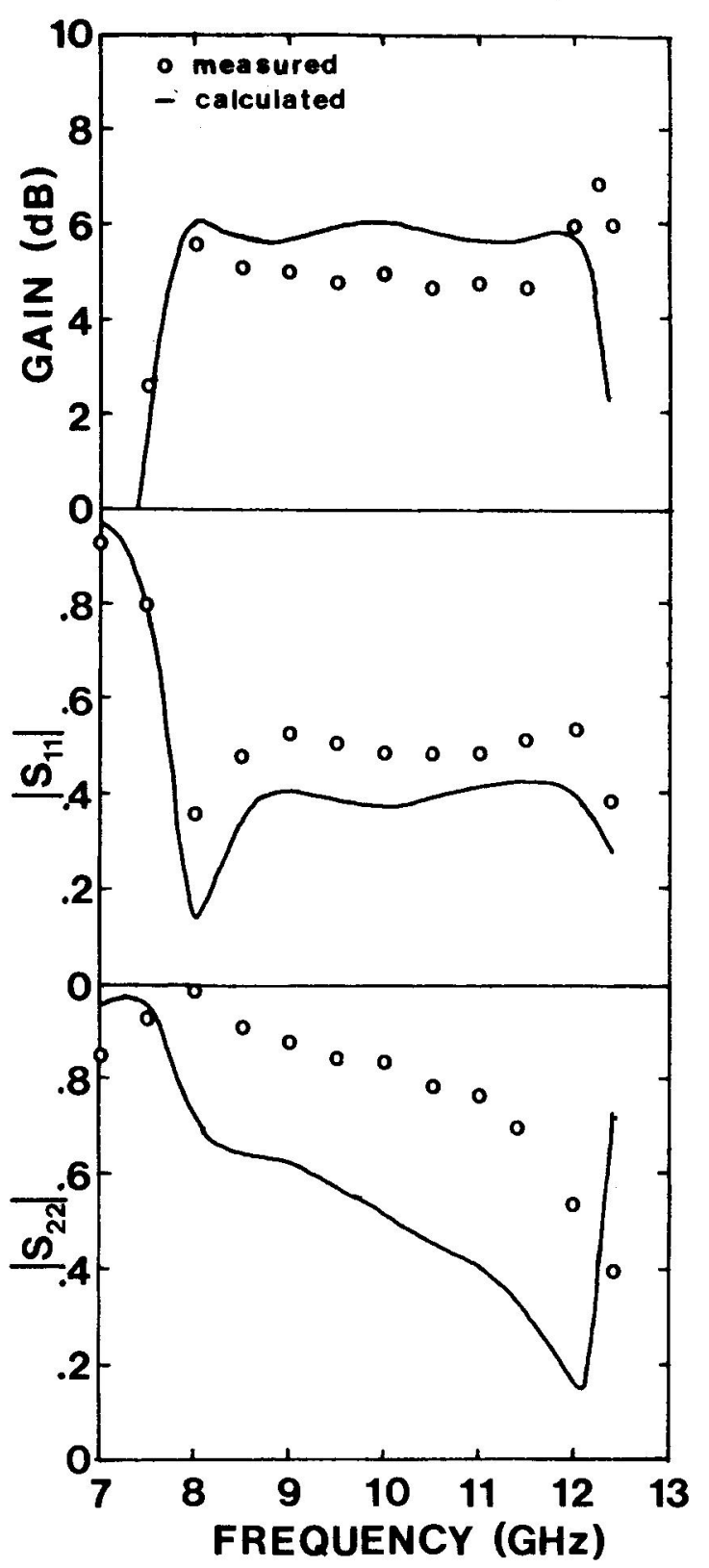

FIG 3a

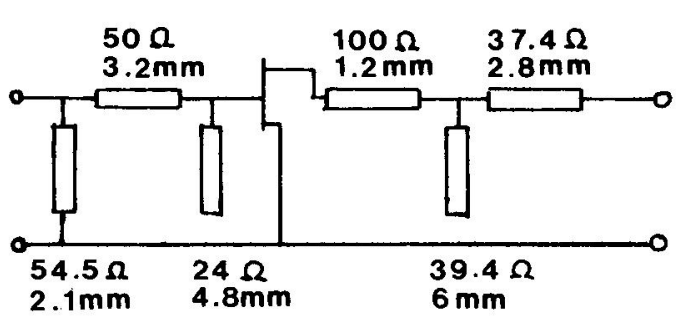

FIG 3b

[5] C.A. Liechti and R.L. Tillman, "Design and Performance of Microwave Amplifiers with GaAs Schottky-Gate Field-Effect Transistors", IEEE Trans. MTr-22, pp. 510-517, May 1974. 


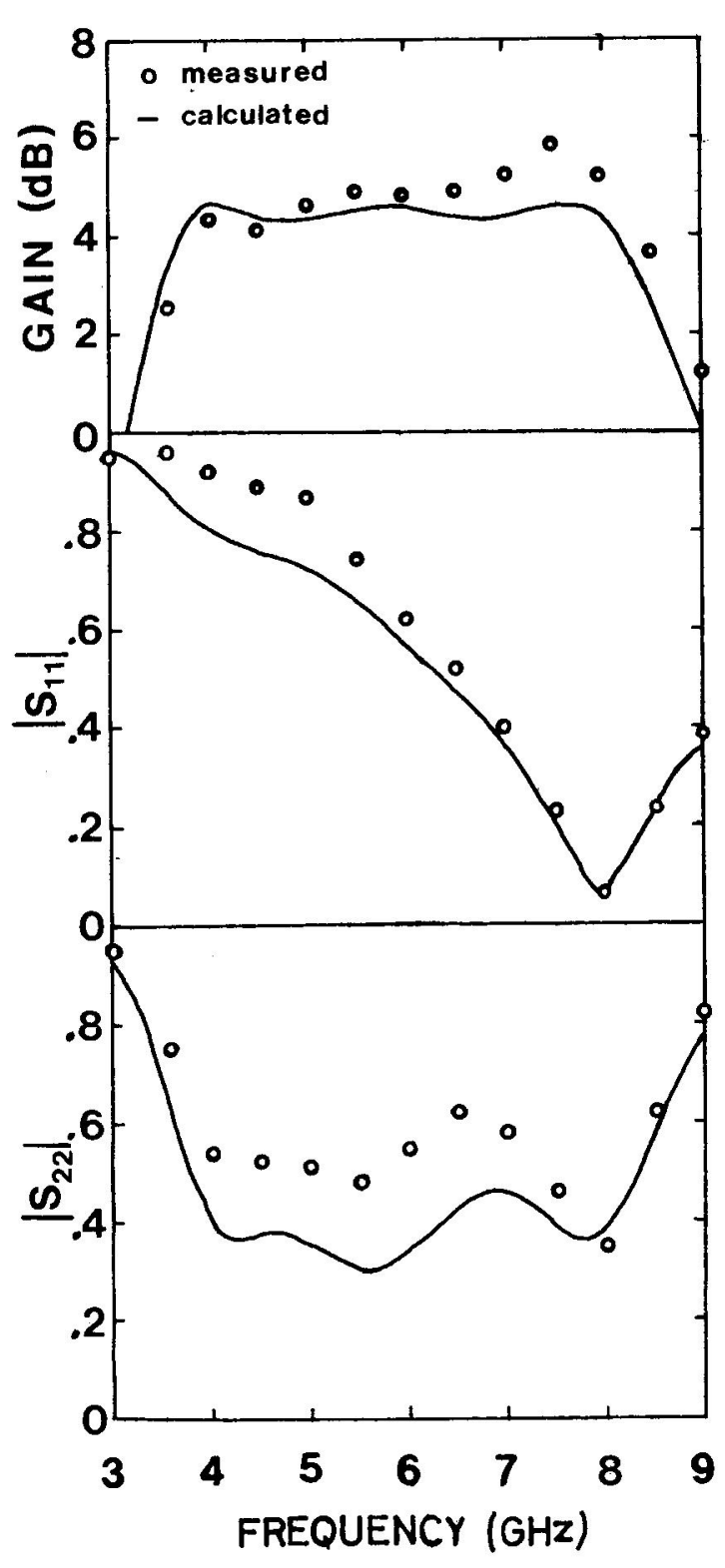

FIG 4a

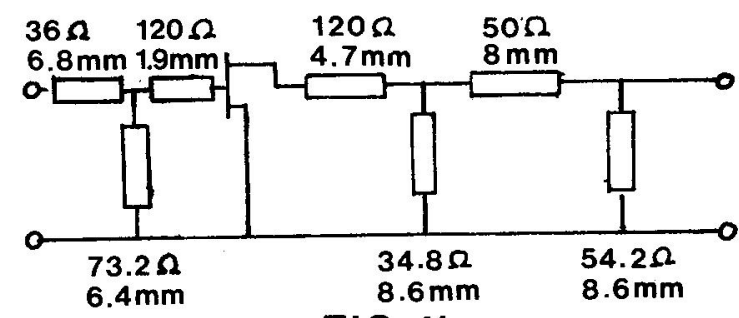

FIG $4 b$

Fig. 4(a) Measured and calculated performance of a $\mathrm{C}$-band amplifier with a LID packaged GAT 3 .

(b) The amplifier circuit.

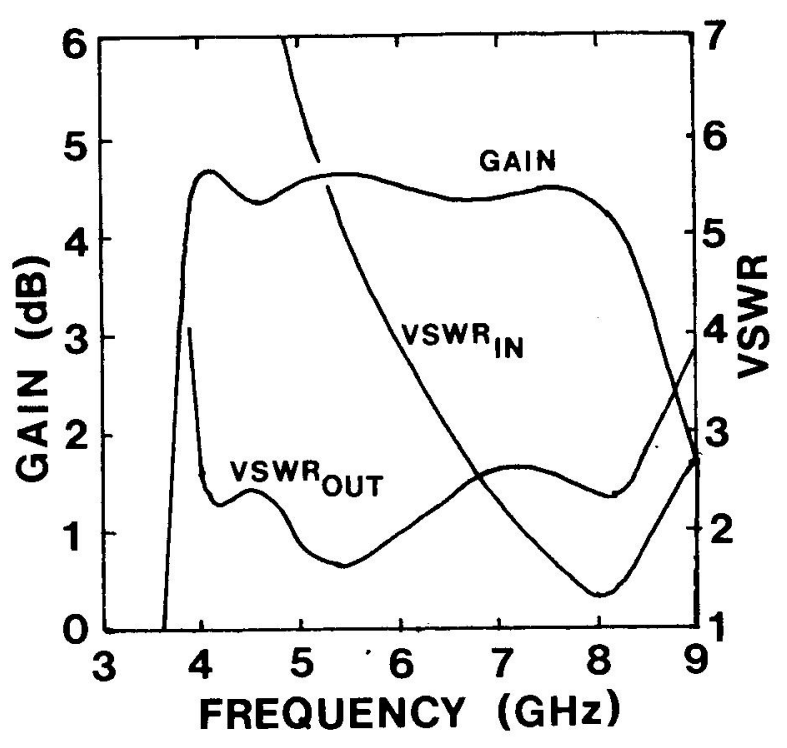

FIG 5a

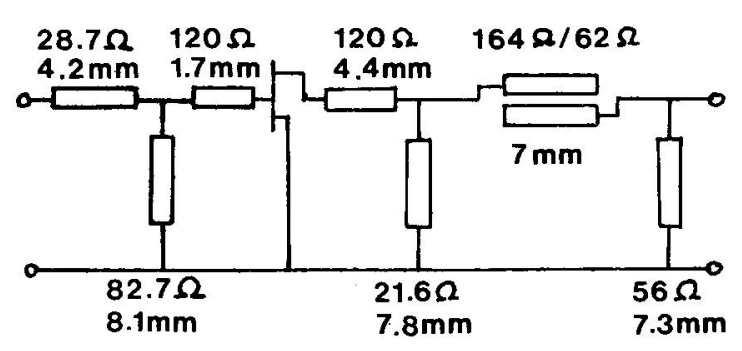

FIG 5b

Fig. 5(a) Power gain and VSWR's of a C-band amplifier with a LID packaged GAT 3 .

(b) The amplifier circuit. 